\title{
Factors Associated With Increased Risk for Dementia in Individuals Age 80 Years or Older With Congestive Heart Failure
}

\author{
Carina Hjelm, Anders Broström, Anna Dahl, Boo Johansson, Mats Fredrikson and Anna \\ Strömberg
}

\section{Linköping University Post Print}

\section{Tweet}

N.B.: When citing this work, cite the original article.

Original Publication:

Carina Hjelm, Anders Broström, Anna Dahl, Boo Johansson, Mats Fredrikson and Anna Strömberg, Factors Associated With Increased Risk for Dementia in Individuals Age 80 Years or Older With Congestive Heart Failure, 2014, Journal of Cardiovascular Nursing, (29), 1, 8290.

http://dx.doi.org/10.1097/JCN.0b013e318275543d

Copyright: Lippincott, Williams \& Wilkins http://www.lww.com/

Postprint available at: Linköping University Electronic Press http://urn.kb.se/resolve?urn=urn:nbn:se:liu:diva-96804 


\section{Factors associated with increased risk of dementia in individuals aged 80 and older with congestive heart failure}

\section{Carina Hjelm RN, PhD Student}

Department of Medical and Health Sciences, Division of Nursing Science, Linköping

University, Sweden

Department of Cardiothoracic Surgery, Linköping University Hospital, Sweden

\section{Anders Broström RN, Associate Professor}

Department of Clinical Neurophysiology, Linköping University Hospital, Sweden

Department of Nursing Science, School of Health Sciences, Jönköping University, Sweden

\section{Anna Dahl PhD, Researcher}

Department of Medical Epidemiology and Biostatistics, Karolinska Institutet, Stockholm, Sweden

Institute of Gerontology, School of Health Sciences, Jönköping University, Jönköping,

Sweden

\section{Boo Johansson Professor}

Department of Psychology, University of Gothenburg, Gothenburg, Sweden

\section{Mats Fredrikson PhD}

Department of Clinical and Experimental Medicine, Faculty of Health Sciences, Linköping,

Sweden

\section{Anna Strömberg RN, Professor}

Department of Medical and Health Sciences, Division of Nursing Science, Linköping

University, Sweden

Department of Cardiology, Linköping University Hospital, Sweden

Correspondence 
Carina Hjelm, RN, PhD Student, Department of Medical and Health Sciences, Division of Nursing Science, 58185 Linköping University, Sweden tel. +46-10-1031787, fax. +46 13 123285, e-mail carina.hjelm@liu.se 


\section{Factors associated with increased risk of dementia in individuals age 80 and older with congestive heart failure}

Background and research objective: An increasing body of evidence shows that individuals diagnosed with congestive heart failure (CHF) are at a higher risk of dementia. However, the prevalence rate of dementia among persons with CHF in the very old has not previously been reported and little is known about the co morbidities that place old persons with CHF at a higher dementia risk. Hence, the aim of this study was to compare the prevalence of dementia in individuals age 80 and older who suffer from CHF with individuals without $\mathrm{CHF}$ and to identify factors related to dementia in individuals diagnosed with CHF.

Methods: A total of 702 participants from the Swedish population-based longitudinal study (OCTO-Twin) were included. The group consisted of same-sex twin pairs age 80 and older and 138 had CHF. Dementia was diagnosed according to criteria in the Diagnostic and Statistical Manual of Mental Disorder (DSM-III-R). Generalised estimation equations (GEE) including sex, age and educational level, waist circumference, diabetes, hypertension, smoking depression, blood values were used in a case control analysis.

Results: Individuals with CHF had a significantly higher prevalence of vascular dementia, $16 \%$ vs. $6 \%(\mathrm{P}<0.001)$, and of all types of dementia, $40 \%$ vs. $30 \%(\mathrm{P}<0.01)$, than those not diagnosed with CHF. The GEE models showed that depression, hypertension, and/or increased levels of homocysteine were all associated with a higher risk of dementia in individuals with CHF. Diabetes was specifically associated with an increased risk of vascular dementia. 
Conclusion: The prevalence of dementia was higher among individuals with CHF than in those without CHF. Diabetes, depression, and hypertension in CHF patients require special attention from health-care professionals since these conditions are associated with an elevated risk of dementia. Higher levels of homocysteine were also found to be a marker of dementia in CHF patients. Further research is needed to identify factors related to dementia in individuals age 80 and older diagnosed with CHF.

Keywords: Alzheimer's disease, dementia, heart failure, octogenarians, risk factors, vascular dementia 


\section{Introduction}

Chronic non-communicable diseases are reaching epidemic proportions worldwide, and heart disease is among the most common. Congestive heart failure (CHF), which originates from a dysfunction in the left ventricular contraction or filling, is the end stage of many forms of heart disease. As a result of increased life expectancy and an increased probability of survival after the onset of heart disease, the prevalence of CHF has risen during the last few decades and is expected to continue increasing. Heart failure is especially common in the older age segments and the prevalence rate is $10-20 \%$ among those 80 years of age and over. ${ }^{1-3}$ The association between severe left ventricular dysfunction and systolic hypotension leading to cerebral hypoperfusion in patients with CHF has revived the old idea of "cardiogenic dementia." 4 This is in line with the evidence that links CHF with an increased risk of cognitive impairments and dementia. ${ }^{5-8}$ Patients with CHF have structural and functional brain changes, losses in grey-matter areas, silent stroke, and decreased cerebral perfusion. ${ }^{9,10}$ It has recently been shown that CHF patients have brain volume reductions in the putamen structures already around the age of 50. ${ }^{11}$ Few data exist on the prevalence of dementia in the oldest old ${ }^{12,13}$ and to our knowledge there are no studies identifying factors related to dementia in patients with CHF.

The identification of predictors or factors associated with increased risk of dementia in patients with $\mathrm{CHF}$ is of significant importance since compromised cognition may be associated with the patient's ability to receive information and adhere to treatment. ${ }^{14}$ Studies have shown higher age, lower cardiac function, non-optimised CHF treatment, lower educational level, prevalence of depression, diabetes, as well as both hypo- and hypertension, smoking, tachycardia and atrial fibrillation to be major determinants for cognitive impairment in individuals with CHF below 80 years of age. ${ }^{15-17}$ However, no previous study has 
investigated factors associated with an increased risk of dementia among very old persons with CHF. Given that CHF is most prevalent in the oldest age segment of the population this is of great public health interest. Further, the knowledge about how various biomarkers relate to dementia among very old persons with CHF is scarce. Biomarkers such as homocystein, creatinine, urea and urate have previously been related to $\mathrm{CHF}$, depression and dementia among elderly, ${ }^{18,19,6,20,21}$ and might also have clinical relevance for diagnosis, risk stratification, and monitoring therapy among elderly patients with CHF. ${ }^{22,19,20}$ The aim of this study was therefore to compare the prevalence of dementia in individuals age 80 and older with CHF and those in the same age group without CHF and to identify factors related to dementia in individuals diagnosed with CHF.

\section{Methods}

\section{Design and setting}

The population-based sample consisted of participants from the longitudinal OCTO-twin study. ${ }^{16}$ The sample was drawn from the Swedish Twin Registry, encompassing over $96 \%$ of all twins in Sweden. ${ }^{23}$ The drop-out rates and selection criteria have been described in detail previously. ${ }^{16}$ In total, 351 same-sex twin pairs born 1913 or earlier participated. Questionnaires, health assessment and extensive cognitive tests were collected by trained research nurses in the participants' homes over a 10-year-period from 1991 to 2002. In-person testing (IPT) was carried out at two-year intervals on five measurement occasions. Laboratory tests and data on pharmacological treatment were collected in IPT 2 (1993-1995) and therefore demographic and clinical characteristics are used from IPT 2 to describe the sample and in the analysis. The Regional Ethical Review Board at the Karolinska Institute, Stockholm, Sweden approved the study. 


\section{Data collection}

\section{Clinical data}

Clinical diagnoses such as CHF, obstructive pulmonary disease, angina pectoris, myocardial infarction and stroke were derived from medical records starting in1980 and were reviewed by an experienced physician. ${ }^{17,24}$ A second independent review of the medical records was conducted to ensure the validity and year of the CHF diagnosis. ${ }^{8}$ Information about medications and health problems was gathered from medical records, drug prescriptions, and self-reports. Hypertension was diagnosed if more than one systolic value was higher than 160 $\mathrm{mmHg}$, and/or diastolic values at least $95 \mathrm{mmHg}{ }^{17}$ at the IPTs. The diagnosis of diabetes (i.e., all kinds of diabetes) included self-reported data or data from medical records.

Depression included sporadic and iterated diagnosed episodes of depressed mood documented in medical records. Creatinine, urea, urate and homocysteine sodium, potassium, albumin, calcium, cobalamine, folat, free thyroxin and free prostate specific antigen were collected in IPT 2.

\section{Dementia diagnoses}

All individuals suspected of having dementia were discussed at a consensus diagnosis conference where all available information including a review of medical records, test protocols, and an informant interview about memory and cognitive problems was used in the diagnostic procedure. ${ }^{25}$ Dementia was diagnosed according to the then current criteria in the Diagnostic and Statistical Manual of Mental Disorder (DSM-III-R). ${ }^{26}$ Differential diagnoses for Alzheimer's disease, vascular dementia and mixed dementia were made according to the criteria for Alzheimer's disease published by the National Institute of Neurological and Communicative Disorders and Stroke/ Alzheimer's Disease and Related Disorders Association (NINCDS/ADRDA) ${ }^{27}$ and the criteria for vascular dementia issued by the National Institute of Neurological Disorders and Stroke (NINDS) after an International 
Workshop supported by the Association Internationale pour la Recherche et l'Enseignement en Neurosciences (AIREN) (AIREN) (NINDS-AIREN). ${ }^{28,28}$ In this study, dementia included Alzheimer's disease, vascular- unclassified- mixed- and secondary dementia.

\section{Instrumentation}

The well validated Mini Mental State Examination (MMSE) ${ }^{29,30}$ is considered to be a satisfactory screening instrument for dementia and can be used to sample various functions including orientation, memory, attention, ability to follow verbal and written commands, and ability to write. The MMSE takes approximately 5-15 minutes to perform and the maximum score is $30 .{ }^{30}$ A score $\geq 28$ is considered to indicate normal cognitive function, $\geq 25-<28$ to indicate mild cognitive impairment, and MMSE $\leq 24$ to indicate cognitive impairment with a high risk for dementia. ${ }^{31}$

Draw a Clock is one part of the administered Clock Test. The task requires attention and concentration, numerical sequencing, visual-spatial analysis, execution and abstract conceptualisation and planning. ${ }^{32}$ It is often used in brief cognitive assessments when screening for Alzheimer's disease and other types of dementia. A maximum score of 5 can be achieved. If dichotomised, a score of 4-5 is considered to indicate normal cognition while 0-3 indicates cognitive impairment. The Draw a Clock Test has demonstrated good inter-rater reliability. $^{29}$ 


\section{Statistical procedures}

Univariate statistics were used to characterise differences between $\mathrm{CHF}$ and non-CHF participants. Differences between the groups regarding demographical and clinical data were analysed using independent samples $t$ test and Chi-squared test. MMSE and Draw a Clock (dichotomous variables) were analysed using Chi-square test. Pearson's correlation between MMSE and Draw a Clock were performed. A p-value of $<0.05$ was considered statistically significant based on two tailed tests. Statistical analyses were performed using SPSS version 17.0. The Generalised estimation equations (GEE) were performed on all types of dementia, vascular dementia, and Alzheimer's disease to analyse factors from models related to an increased risk of dementia among persons with CHF using SAS Proc Mixed multilevel modelling. The GEE model is conceptually equivalent to logistic regression, but controls for the clustering of twins within a pair, since independence in twin pairs could not be assumed. Pearson's correlation was performed to evaluate the relation between biochemical variables and dementia before inclusion in the models.

In the first model sex, age and educational level, waist circumference, diabetes, hypertension, smoking and depression were entered as covariates. In Model 2 creatinine, urea, urate and homocysteine were additionally controlled for. ${ }^{33}$

A non-linear relationship between risk of dementia and blood pressure was also controlled for. There was no evidence for an inverted or U-shaped effect between blood pressure and risk of dementia, so it was therefore decided to use blood pressure as a continuous variable in the GEE models. 


\section{Results}

\section{Study population}

Table 1 shows sample characteristics for the participants at IPT 2.

Insert Table 1

Individuals with CHF had a higher prevalence of MMSE scores $\leq 24$ (the commonly used cutoff score used as an indication of dementia) on all measurement occasions except the last (Figure 1), compared to persons without CHF. Individuals with CHF also had significantly higher prevalence of MMSE scores at IPT 1-3 when a cut-off score of $\geq 25$ and $<28$ for defining mild global cognitive impairment was used, but no differences were seen in IPT 4 and 5 although the association pointed in the same direction. As dementia cause cognitive impairment, we also wanted to examine if cognitive abilities were affected in non-dementia cases. When excluding those with dementia, individuals with CHF still had lower cognitive abilities using both the MMSE cut-off $\leq 24$ and $\geq 25$ and $<28$. The frequency of missing data in MMSE $\leq 24$ increased across IPT 1-5 and was higher in the CHF group (6.3\% at IPT 1 vs. $86.1 \%$ at IPT 5) compared to the non-CHF group (1.1\% at IPT 1 vs. $62.9 \%$ at IPT 5), including dementia cases.

Insert Figure 1

The CHF group scored significantly worse on the Draw a Clock test compared to the nonCHF group in IPT 1-3 and in IPT 5 (Figure 2); the results did not change when individuals diagnosed with dementia were excluded. As with the MMSE scores, individuals diagnosed with CHF had a higher drop-out rate (20\% at IPT 1 vs. $89 \%$ at IPT 5) than the non-CHF group (8\% missing at IPT 1 vs. $67 \%$ at IPT 5) in the Draw a Clock test. The correlation between MMSE and the Clock Drawing test for IPT 1-5 ranged between 0.81 and 0.87. 
Insert Figure 2

\section{Prevalence of dementia}

The CHF group had a significantly higher prevalence of all types of dementia and vascular dementia across all measurement occasions than the non-CHF group (Table 2). There was no significant difference between the CHF and non-CHF group in the prevalence of Alzheimer's disease.

Insert Table 2

\section{Factors associated with the risk of dementia among individuals with CHF}

The GEE models showed that higher prevalence of depression (model 1), hypertension and/or increased levels of homocysteine (model 2) were associated with greater risk for all types of dementia in individuals with CHF (Table 3). Furthermore, diabetes was associated with vascular dementia in the CHF population (model 1 and 2) (Table 4). Sex, age, education, waist circumference, smoking, creatinine, urea and urate were not found to be significant for any of the dementia diagnoses or in any model. Model 2 showed a significant improvement in model fit compared to model 1, based on the log likelihood (LL) ratio test (LR), for all types of dementia $\mathrm{LR}=* 2(-301.736--234.798), \mathrm{LL}=133.9(4), \mathrm{p}<0.001$, and for vascular dementia $\mathrm{LR}=* 2(-110.977--78.373), \mathrm{LL}=65.2(4), \mathrm{p}<0.001$. No factors were significantly associated with Alzheimer's disease in individuals with CHF in any of the models.

Insert Table 3 and 4

(2) 


\section{Discussion}

This longitudinal study of octogenerians showed that the prevalence of mild cognitive impairment (range CHF 72-78 \%, non CHF 55-70\%) and cognitive impairment with a risk of dementia (range CHF 42-54\%, non CHF 23-40\%) measured with MMSE and Clock test (range CHF 29-40, non CHF 19-20\%) was higher in the CHF population than in the non-CHF group, both when individuals with dementia were included and when they were excluded. This indicates that those with $\mathrm{CHF}$ who are not diagnosed with dementia also have a lower cognitive performance than those without CHF. Moreover, it was found that the CHF group had a significantly higher prevalence of all types of dementia (CHF 37-39\% compared to non CHF 30-31\%) and vascular dementia (CHF 15-16\% compared to non CHF 5-7\%) no difference between the groups was found regarding the prevalence of Alzheimer's disease. Qiu et al. showed that $15 \%$ of the individuals aged $>75$ years were diagnosed with dementia and $19.5 \%$ with Alzheimer's disease. CHF increased the risk of dementia by $40 \%$ and Alzheimer's disease by $54 \% .^{21}$

To our knowledge this is the first study to report on risk factors associated with dementia among those above 80 years of age who have been diagnosed with CHF. We found that the prevalence of depression and hypertension, as well as higher levels of homocysteine, were significantly associated with an increased risk of dementia in very old persons with CHF. The link between depression and vascular dementia might be due to the impact of an overall greater vascular burden. ${ }^{34}$ Other studies have shown that patients with vascular dementia experience a higher degree of depression and anxiety than patients with Alzheimers's disease.

${ }^{34}$ Depression and vascular disease share common pathophysiological processes and genetic determinants. It has also been proposed that depression can be an early sign of dementia, a 
catalyst of the clinical manifestation of dementia, and may cause impairments in the hippocampus through the glucocorticoid cascade. ${ }^{34,35}$

Although it is well known that the midlife hypertension is associated with an increased risk of cognitive impairments and dementia, the association between blood pressure and dementia in old age is not clear-cut. Results from population-based studies show diverse results and link both hypotension and hypertension to an increased risk of cognitive impairments ${ }^{36,37}$, and dementia while others have even reported a U-shaped association. ${ }^{38}$ Neuroimaging studies of CHF patients have demonstrated that cerebral hypoperfusion is prospectively associated with significant brain injuries ${ }^{10,11}$ and the clinical onset and progression of dementia. ${ }^{21,39}$ Our results indicate that among persons with CHF hypertension is a risk factor of dementia. Comparing the results regarding blood pressure in the present study with recent studies on risk factors of dementia among persons with $\mathrm{CHF}^{1,40}$ may be difficult since treatment strategies have changed. The participants in the present study had not been given modern pharmacological CHF therapy, for example only $10 \%$ had been prescribed an ACE inhibitor. The mean systolic blood pressure was 159 and mean diastolic blood pressure 84 . These values are defined as indicating high blood pressure according to present guidelines for CHF treatment with a therapeutic target of blood pressure within $\leq 140 / 90$ and $\leq 130 / 80 \mathrm{mmHg}{ }^{1}$ Hence, it would be interesting to compare the effects of modern blood pressure therapy on cognitive performance and development of dementia diseases among individuals with CHF.

The results of this study showed that homocysteine was a marker of all types of dementia in patients with CHF. Hyperhomocysteinemia has for many years been associated with cardiovascular disease such as atherosclerosis and CHF and to correlate with brain natriuretic peptide, a biochemical marker of heart failure. ${ }^{41}$ Several studies ${ }^{42,43}$ have shown that such a 
high level of homocysteine is a strong independent marker for the development of dementia and Alzheimer's disease, independently of several major confounders such as hypertension, smoking status, diabetes and BMI. However, these studies were performed among general elderly populations, not specifically among those suffering from CHF.

We also found that diabetes was the only significant pervasive factor associated with vascular dementia in the CHF population. Previous studies ${ }^{44,45}$ have shown that diabetes is related both to cognitive decline and dementia. In particular, diabetes has been associated with an increased risk of dementia of vascular origin. ${ }^{46}$

\section{Implications for care of patients with $\mathrm{CHF}$}

Better knowledge of dementia in general, as well as of factors associated with risk of dementia is of importance for health care professionals working with CHF patients. Awareness of the vulnerability of CHF patients who are at increased risk of dementia, that is individuals with a higher vascular burden, is of great importance since they are in need of special support. Routine management of CHF should include systematic assessment of cognitive performance and detection of dementia. Individuals with a combination of CHF and other multiple chronic conditions have a poorer prognosis. They also seem to be prone to poorer self-care. ${ }^{47} 14$ Self-care requires the cognitive abilities to learn, perceive, interpret and respond, all of which are increasingly more difficult for individuals with dementia. Agerelated inability to detect and interpret symptoms may therefore be an important cause for poor self-care ${ }^{14}$ and caregivers need to help patients and partners with symptom interpretation in this specific CHF group. 


\section{Limitations}

The longitudinal design with inclusion of a large population-based sample of individuals over the age of 80 is an important strength of this study. However, the data collection was performed in 1991-2002. The medical treatment of CHF has developed since then, which needs to be taken into account. Furthermore, the CHF diagnosis was derived from medical records; only a few individuals were diagnosed using echocardiography and no New York Heart Association classifications were documented. At present additional objective data are required (e.g., Doppler echocardiography or natriuretic peptides) regarding cardiac function in addition to subjective symptoms/signs of the patient in order to make the diagnosis of CHF. A formal screening instrument for depression was not used in the statistical analysis. However, data on clinically diagnosed depressions were collected from the medical records.

MMSE and Draw a Clock should be seen as dementia screening devices and the test scores might serve as crude indications of dementia and cognitive impairment. ${ }^{48}$

\section{Conclusion}

Although there is no cure for dementia, early identification is important for treatment of the symptoms and healthcare planning. It was found that the prevalence of dementia was higher among individuals with $\mathrm{CHF}$ and that depression and hypertension were significantly associated with an elevated risk of dementia. Furthermore, increased levels of homocysteine were found to be a marker of dementia in CHF patients. Diabetes was also related to a greater risk of vascular dementia. Further investigations across a broader spectrum of factors associated with dementia in individuals age 80 and older with $\mathrm{CHF}$ are required, including markers of inflammation, multi-morbidity, nutrition, use of alcohol and drugs, sleep, life stress and social support. 
Conflict of interest: None of the authors report any conflicts of interest.

\section{What is new and important?}

- Dementia is more prevalent among individuals aged 80 and older with CHF, with almost $40 \%$ suffering from some type of dementia.

- CHF patients suffering from diabetes, depression and/or arterial hypertension are at greater risk of dementia and require special attention from healthcare professionals.

- Higher levels of homocysteine in the CHF population seem to be a marker of increased risk of dementia. 


\section{References}

1. Dickstein $\mathrm{K}$, Cohen-Solal $\mathrm{A}$, Filippatos $\mathrm{G}$, et al. ESC guidelines for the diagnosis and treatment of acute and chronic heart failure 2008. Eur J Heart Fail. Oct 2008;10(10):933-989.

2. Plassman BL, Langa KM, Fisher GG, et al. Prevalence of dementia in the United States: the aging, demographics, and memory study. Neuroepidemiology. 2007;29(1-2):125-132.

3. Qiu C, De Ronchi D, Fratiglioni L. The epidemiology of the dementias: an update. Curr Opin Psychiatry. Jul 2007;20(4):380-385.

4. Rosemberg GA, Haaland, R.Y. Cardiogenic dementia. Lancet. 1981;2:1171.

5. Heckman GA, Patterson CJ, Demers C, St Onge J, Turpie ID, McKelvie RS. Heart failure and cognitive impairment: challenges and opportunities. Clin Interv Aging. 2007;2(2):209-218.

6. Pressler SJ, Subramanian U, Kareken D, et al. Cognitive deficits in chronic heart failure. Nurs Res. Mar-Apr 2010;59(2):127-139.

7. Pressler SJ, Subramanian U, Kareken D, et al. Cognitive deficits and health-related quality of life in chronic heart failure. J Cardiovasc Nurs. May-Jun 2010;25(3):189-198.

8. Hjelm C, Dahl A, Brostrom A, Martensson J, Johansson B, Stromberg A. The influence of heart failure on longitudinal changes in cognition among individuals 80 years of age and older. $J$ Clin Nurs. Apr 2011;21(7-8):994-1003.

9. Pressler SJ. Cognitive functioning and chronic heart failure: a review of the literature (2002July 2007). J Cardiovasc Nurs. May-Jun 2008;23(3):239-249.

10. Woo MA, Macey PM, Keens PT, et al. Functional abnormalities in brain areas that mediate autonomic nervous system control in advanced heart failure. J Card Fail. Aug 2005;11(6):437446.

11. Kumar R, Nguyen HD, Ogren JA, et al. Global and regional putamen volume loss in patients with heart failure. Eur J Heart Fail. Jun 2011;13(6):651-655.

12. James BD, Bennett DA, Boyle PA, Leurgans S, Schneider JA. Dementia from Alzheimer disease and mixed pathologies in the oldest old. JAMA. May 2 2012;307(17):1798-1800.

13. Savva GM, Wharton SB, Ince PG, Forster G, Matthews FE, Brayne C. Age, neuropathology, and dementia. N Engl J Med. May 28 2009;360(22):2302-2309.

14. Riegel B, Dickson VV, Cameron J, et al. Symptom recognition in elders with heart failure. $J$ Nurs Scholarsh. Mar 2010;42(1):92-100.

15. Debette S, Bauters C, Leys D, Lamblin N, Pasquier F, de Groote P. Prevalence and determinants of cognitive impairment in chronic heart failure patients. Congest Heart Fail. JulAug 2007;13(4):205-208.

16. McClearn GE, Johansson B, Berg S, et al. Substantial genetic influence on cognitive abilities in twins 80 or more years old. Science. Jun 6 1997;276(5318):1560-1563.

17. Nilsson SE, Johansson B, Berg S, Karlsson D, McClearn GE. A comparison of diagnosis capture from medical records, self-reports, and drug registrations: a study in individuals 80 years and older. Aging Clin Exp Res. Jun 2002;14(3):178-184.

18. Nilsson SE, Takkinen S, Tryding N, et al. Association of biochemical values with morbidity in the elderly: a population-based Swedish study of persons aged 82 or more years. Scand J Clin Lab Invest. 2003;63(7-8):457-466.

19. Shah RV, Givertz MM. Managing acute renal failure in patients with acute decompensated heart failure: the cardiorenal syndrome. Curr Heart Fail Rep. Sep 2009;6(3):176-181.

20. Cacciapuoti F. Hyper-homocysteinemia: a novel risk factor or a powerful marker for cardiovascular diseases? Pathogenetic and therapeutical uncertainties. J Thromb Thrombolysis. Jul 2011;32(1):82-88.

21. Qiu C, Xu W, Winblad B, Fratiglioni L. Vascular risk profiles for dementia and Alzheimer's disease in very old people: a population-based longitudinal study. J Alzheimers Dis. 2010;20(1):293-300.

22. Bohm M, Voors AA, Ketelslegers JM, et al. Biomarkers: optimizing treatment guidance in heart failure. Clin Res Cardiol. Nov 2011;100(11):973-981.

23. Cederlöf R. LU. In Twin Research: Part C, Biology and Epidemiology1978.

24. ICD-10. International Statistical Classification of diseases and Health problems. Geneva: World Health Organisation; 1992.

25. Pedersen NL, Gatz M, Berg S, Johansson B. How heritable is Alzheimer's disease late in life? Findings from Swedish twins. Ann Neurol. Feb 2004;55(2):180-185.

26. American Psychiatric Association, ed Diagnostic and statistical manual of mental disorders. Rev. 3rd. ed. Washington, DC: Author1987. 
27. McKhann G, Drachman D, Folstein M, Katzman R, Price D, Stadlan EM. Clinical diagnosis of Alzheimer's disease: report of the NINCDS-ADRDA Work Group under the auspices of Department of Health and Human Services Task Force on Alzheimer's Disease. Neurology. Jul 1984;34(7):939-944.

28. Roman GC, Tatemichi TK, Erkinjuntti T, et al. Vascular dementia: diagnostic criteria for research studies. Report of the NINDS-AIREN International Workshop. Neurology. Feb 1993;43(2):250-260.

29. McDowell I NC, ed Measuring Health: A Guide to rating Scales and Questionnaires. 2nd ed ed. New York: NY: Oxford University Press; 1996.

30. Folstein MF, Folstein SE, McHugh PR. "Mini-mental state". A practical method for grading the cognitive state of patients for the clinician. J Psychiatr Res. Nov 1975;12(3):189-198.

31. Crum RM, Anthony JC, Bassett SS, Folstein MF. Population-based norms for the Mini-Mental State Examination by age and educational level. JAMA. May 12 1993;269(18):2386-2391.

32. Goodglass H, Kaplan E. The Assessment of Aphasia and Related Disorders. Philadelphia: Lea \& Febiger; 1983.

33. Zeger SL, Liang KY. Longitudinal data analysis for discrete and continuous outcomes. Biometrics. Mar 1986;42(1):121-130.

34. Camus V, Kraehenbuhl H, Preisig M, Bula CJ, Waeber G. Geriatric depression and vascular diseases: what are the links? J Affect Disord. Jul 2004;81(1):1-16.

35. Jorm AF. History of depression as a risk factor for dementia: an updated review. Aust $N Z J$ Psychiatry. Dec 2001;35(6):776-781.

36. Molander L, Gustafson Y, Lovheim H. Low blood pressure is associated with cognitive impairment in very old people. Dement Geriatr Cogn Disord. 2010;29(4):335-341.

37. Nilsson SE, Read S, Berg S, Johansson B, Melander A, Lindblad U. Low systolic blood pressure is associated with impaired cognitive function in the oldest old: longitudinal observations in a population-based sample 80 years and older. Aging Clin Exp Res. Feb 2007;19(1):41-47.

38. Thorvaldsson V, Skoog I, Hofer SM, et al. Nonlinear blood pressure effects on cognition in old age: Separating between-person and within-person associations. Psychol Aging. Jun 2012;27(2):375-383.

39. Ruitenberg A, den Heijer T, Bakker SL, et al. Cerebral hypoperfusion and clinical onset of dementia: the Rotterdam Study. Ann Neurol. Jun 2005;57(6):789-794.

40. Qiu C, Winblad B, Fratiglioni L. The age-dependent relation of blood pressure to cognitive function and dementia. Lancet Neurol. Aug 2005;4(8):487-499.

41. Herrmann W, Herrmann M, Joseph J, Tyagi SC. Homocysteine, brain natriuretic peptide and chronic heart failure: a critical review. Clin Chem Lab Med. 2007;45(12):1633-1644.

42. Seshadri S. Elevated plasma homocysteine levels: risk factor or risk marker for the development of dementia and Alzheimer's disease? J Alzheimers Dis. Aug 2006;9(4):393-398.

43. Ravaglia G, Forti $P$, Maioli $F$, et al. Homocysteine and folate as risk factors for dementia and Alzheimer disease. Am J Clin Nutr. Sep 2005;82(3):636-643.

44. Awad N, Gagnon M, Messier C. The relationship between impaired glucose tolerance, type 2 diabetes, and cognitive function. J Clin Exp Neuropsychol. Nov 2004;26(8):1044-1080.

45. Cukierman T, Gerstein HC, Williamson JD. Cognitive decline and dementia in diabetes-systematic overview of prospective observational studies. Diabetologia. Dec 2005;48(12):2460-2469.

46. Hassing LB, Johansson B, Nilsson SE, et al. Diabetes mellitus is a risk factor for vascular dementia, but not for Alzheimer's disease: a population-based study of the oldest old. Int Psychogeriatr. Sep 2002;14(3):239-248.

47. Dickson VV, Buck H, Riegel B. A qualitative meta-analysis of heart failure self-care practices among individuals with multiple comorbid conditions. J Card Fail. May 2011;17(5):413-419.

48. Dahl A, Berg S, Nilsson SE. Identification of dementia in epidemiological research: a study on the usefulness of various data sources. Aging Clin Exp Res. Oct 2007;19(5):381-389. 


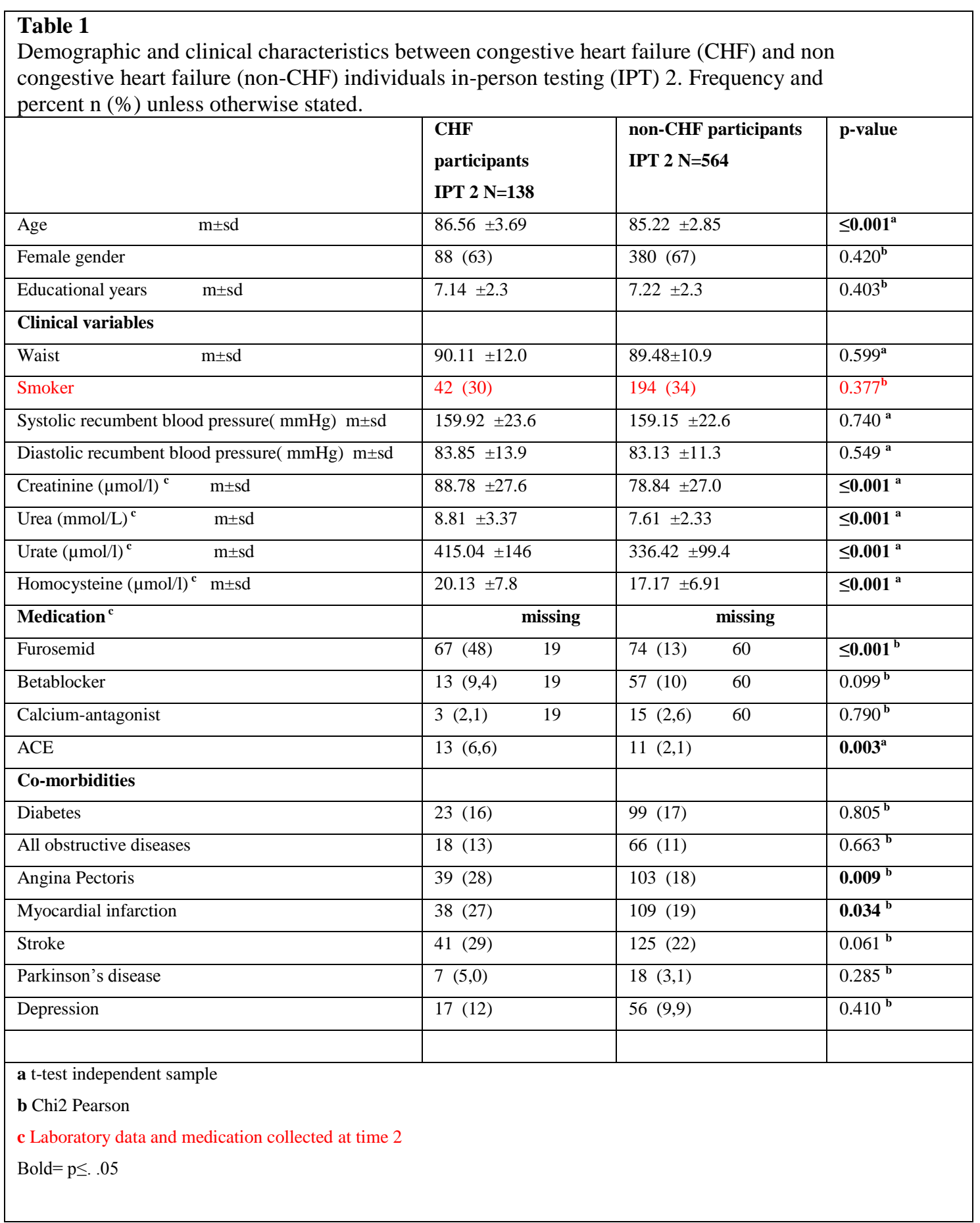




\section{Figure 1}

Prevalence of mild global cognitive dysfunction (MMSE $\geq 25$ and $<28$ ) and cognitive dysfunction (MMSE $\leq 24)$ in congestive heart failure (CHF) and non-congestive heart failure (non-CHF) groups over time, including dementia cases. Percent of frequency score ${ }^{*} \mathrm{p} \leq 0.05$
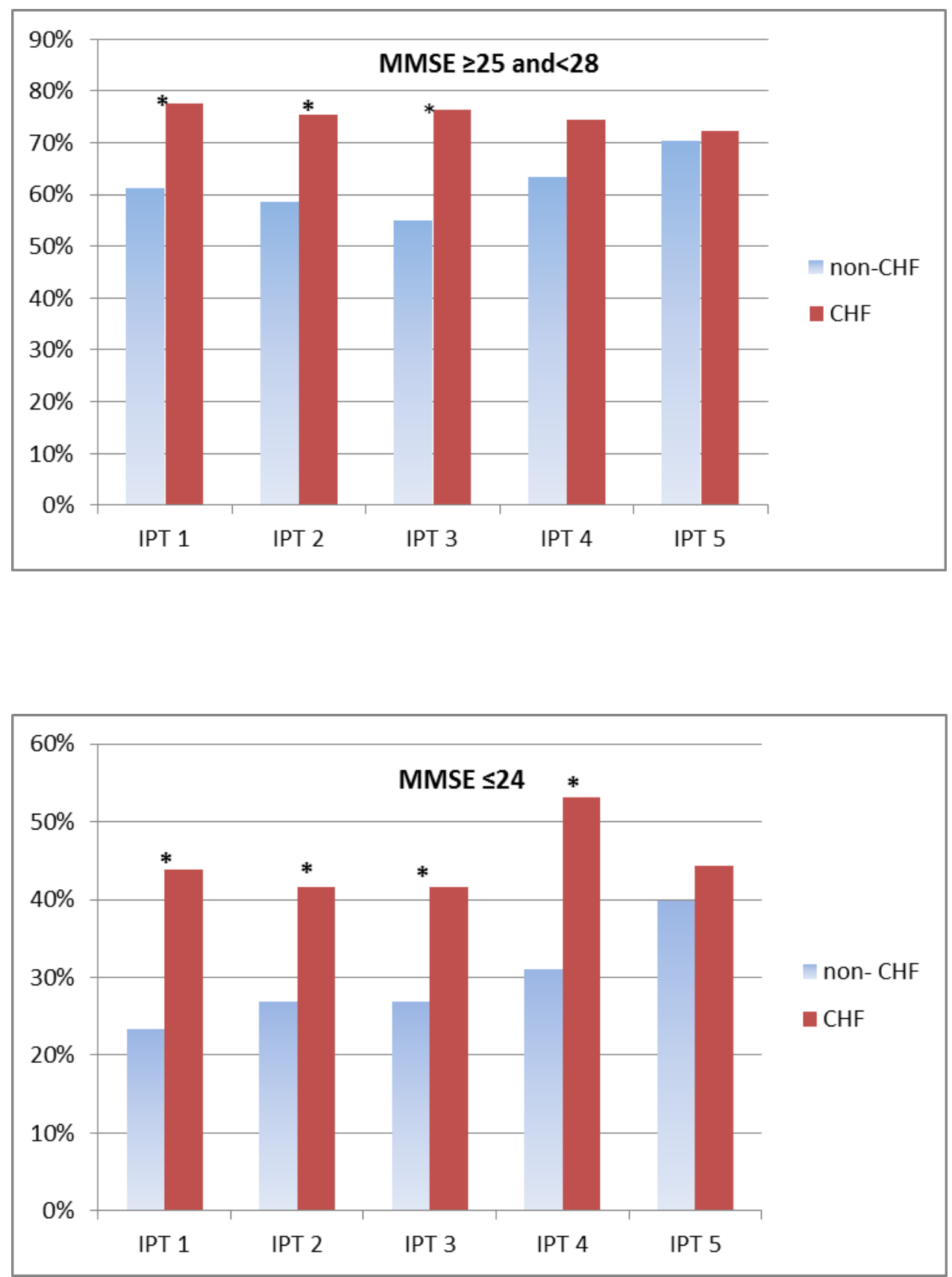


\section{Figure 2}

Prevalence of cognitive impairment (Draw a clock 0-3) in congestive heart failure (CHF) and non-congestive heart failure (non-CHF) groups over time, including dementia cases. Percent of frequency score $* p \leq 0.05$

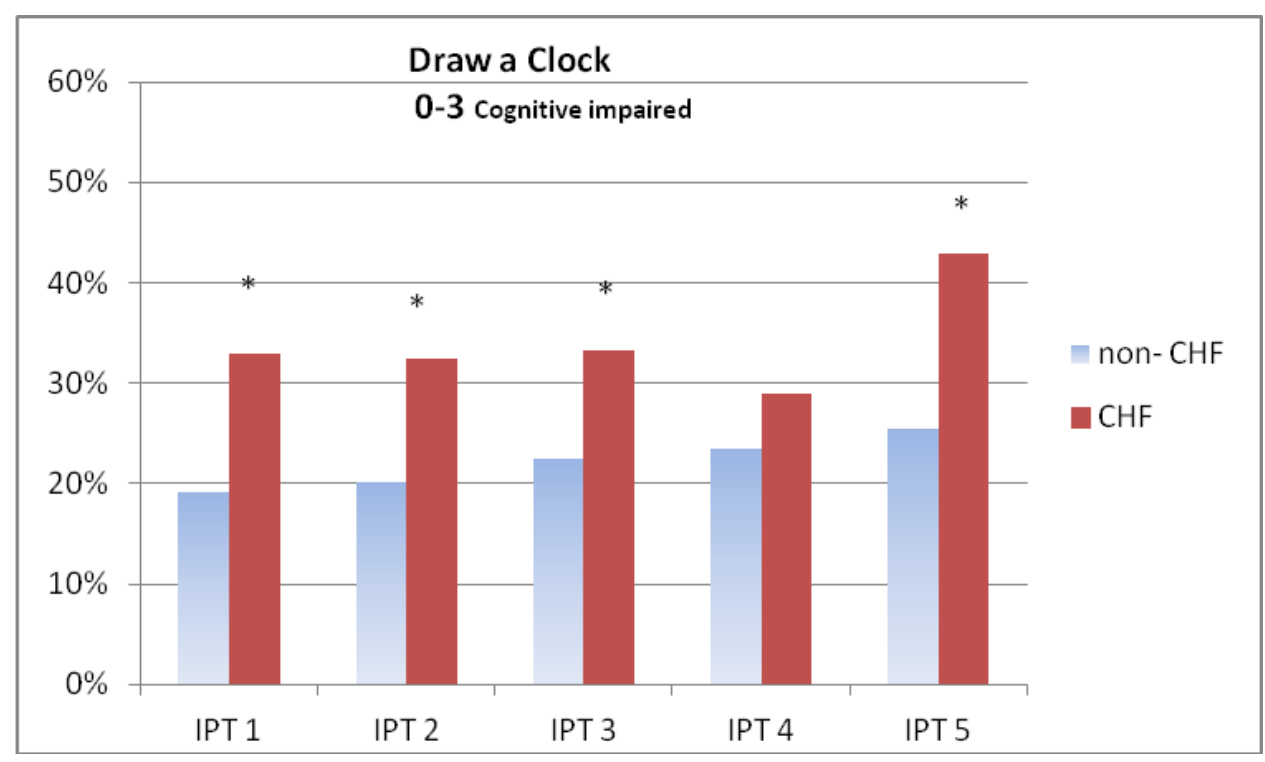


Table 2

Prevalence of dementia diagnoses In Person Testing (IPT) 1-5 between congestive heart failure (CHF) and non- congestive heart failure

individuals (non-CHF)

\begin{tabular}{|c|c|c|c|c|c|c|c|c|c|c|c|c|c|c|c|}
\hline & \multicolumn{3}{|c|}{ IPT1 } & \multicolumn{3}{|c|}{ IPT2 } & \multicolumn{3}{|l|}{ IPT3 } & \multicolumn{3}{|c|}{ IPT4 } & \multicolumn{3}{|l|}{ IPT5 } \\
\hline $\begin{array}{l}\text { Alzheimer's } \\
\text { disease }\end{array}$ & $\begin{array}{l}16 \\
17 \%\end{array}$ & $\begin{array}{l}111 \\
18 \%\end{array}$ & 0.886 & $\begin{array}{l}26 \\
19 \%\end{array}$ & $\begin{array}{l}101 \\
18 \%\end{array}$ & 0.806 & $\begin{array}{l}34 \\
18 \%\end{array}$ & $\begin{array}{l}93 \\
18 \%\end{array}$ & 0.913 & $\begin{array}{l}34 \\
17 \%\end{array}$ & $\begin{array}{l}93 \\
18 \%\end{array}$ & 0.827 & $\begin{array}{l}34 \\
17 \%\end{array}$ & $\begin{array}{l}93 \\
18 \%\end{array}$ & 0.827 \\
\hline $\begin{array}{l}\text { Vascular } \\
\text { dementia }\end{array}$ & $\begin{array}{l}15 \\
16 \%\end{array}$ & $\begin{array}{l}42 \\
7 \%\end{array}$ & 0.007 & $\begin{array}{l}22 \\
16 \%\end{array}$ & $\begin{array}{l}35 \\
6 \%\end{array}$ & 0.001 & $\begin{array}{l}29 \\
15 \%\end{array}$ & $\begin{array}{l}28 \\
5 \%\end{array}$ & $<0.001$ & $\begin{array}{l}29 \\
15 \%\end{array}$ & $\begin{array}{l}28 \\
5 \%\end{array}$ & $<0.001$ & $\begin{array}{l}29 \\
15 \%\end{array}$ & $\begin{array}{l}28 \\
5 \%\end{array}$ & $<0.001$ \\
\hline $\begin{array}{l}\text { All } \\
\text { dementia }\end{array}$ & $\begin{array}{l}37 \\
39 \%\end{array}$ & $\begin{array}{l}188 \\
31 \%\end{array}$ & 0.126 & $\begin{array}{l}56 \\
41 \%\end{array}$ & $\begin{array}{l}169 \\
30 \%\end{array}$ & 0.019 & $\begin{array}{l}73 \\
38 \%\end{array}$ & $\begin{array}{l}152 \\
30 \%\end{array}$ & 0.046 & $\begin{array}{l}73 \\
37 \%\end{array}$ & $\begin{array}{l}152 \\
30 \%\end{array}$ & 0.071 & $\begin{array}{l}73 \\
37 \%\end{array}$ & $\begin{array}{l}152 \\
30 \%\end{array}$ & 0.886 \\
\hline $\begin{array}{l}\text { Total } \\
\text { participants }\end{array}$ & 95 & 607 & & 138 & 564 & & 192 & 510 & & 195 & 507 & & 195 & 507 & \\
\hline
\end{tabular}




\begin{tabular}{|c|c|c|c|c|}
\hline \multicolumn{5}{|c|}{$\begin{array}{l}\text { Table } 3 \\
\text { Generalised estimation equation parameter estimate for the mean response structure of All types } \\
\text { of dementia among congestive heart failure individuals. A negative mean level value indicates a } \\
\text { negative relationship. }\end{array}$} \\
\hline & \multirow{2}{*}{$\begin{array}{l}\text { Model } 1 \\
\text { Mean Level (SE) }\end{array}$} & \multirow[b]{2}{*}{ p-value } & \multirow{2}{*}{$\begin{array}{l}\text { Model } 2 \\
\text { Mean Level (SE) }\end{array}$} & \multirow[b]{2}{*}{ p-value } \\
\hline All types of dementia & & & & \\
\hline Sex & $0.07(0.28)$ & 0.798 & $0.04(0.33)$ & 0.890 \\
\hline Age & $-0.01(0.03)$ & 0.695 & $-0.02(0.04)$ & 0.571 \\
\hline Education & $-0.00(0.04)$ & 0.978 & $0.01(0.05)$ & 0.826 \\
\hline waist circumference & $0.00(0.01)$ & 0.427 & $0.00(0.01)$ & 0.760 \\
\hline Diabetes & $0.30(0.26)$ & 0.239 & $0.44(0.29)$ & 0.134 \\
\hline Hypertension & $0.32(0.20)$ & 0.108 & $0.45(0.23)$ & 0.048 \\
\hline Smoking & $-0.17(0.24)$ & 0.471 & $-0.00(0.27)$ & 0.986 \\
\hline Depression & $0.59(0.30)$ & 0.049 & $0.74(0.33)$ & 0.024 \\
\hline Creatinine & & - & $-0.00(0.00)$ & 0.880 \\
\hline Urea & & _- & $0.02(0.05)$ & 0.631 \\
\hline Urate & & - & $-0.00(0.00)$ & 0.394 \\
\hline Homocysteine & & - & $0.03(0.01)$ & 0.047 \\
\hline modelfit log likelihood & -301.7 & & -234.8 & \\
\hline \multicolumn{5}{|c|}{$\begin{array}{l}\text { Model } \mathbf{1} \text { adjusted for sex, age, educational level, waist circumference, diabetes, hypertension, } \\
\text { moking and depression. } \\
\text { Model } \mathbf{2} \text { adjusted for sex, age, educational level, waist circumference, diabetes, hypertension, } \\
\text { moking, depression, creatinine, urea, urate and homocysteine. } \\
\text { Bold }=\mathbf{p} \leq \mathbf{0 . 0 5} \text {. }\end{array}$} \\
\hline
\end{tabular}




\begin{tabular}{|c|c|c|c|c|}
\hline \multicolumn{5}{|c|}{$\begin{array}{l}\text { Generalised estimation equation parameter estimate for the mean response structure of Vascular } \\
\text { dementia among congestive heart failure individuals. A negative mean level value indicates a } \\
\text { negative relationship. }\end{array}$} \\
\hline & Model 1 & & Model 2 & \\
\hline $\begin{array}{l}\text { Vascular } \\
\text { dementia }\end{array}$ & Mean Level (SE) & p-value & MeanLevel (SE) & p-value \\
\hline Sex & $-0.04(0.53)$ & 0.937 & $0.09(0.66)$ & 0.892 \\
\hline Age & $-0.05(0.07)$ & 0.491 & $-0.07(0.09)$ & 0.453 \\
\hline education & $-0.02(0.09)$ & 0.800 & $0.00(0.10)$ & 0.978 \\
\hline waist circumference & $0.00(0.01)$ & 0.707 & $-0.00(0.02)$ & 0.721 \\
\hline Diabetes & $0.99(0.41)$ & 0.016 & $1.34(0.50)$ & 0.007 \\
\hline hypertension & $0.73(0.39)$ & 0.063 & $0.79(0.47)$ & 0.097 \\
\hline Smoking & $0.16(0.46)$ & 0.727 & $0.48(0.53)$ & 0.365 \\
\hline depression & $0.57(0.52)$ & 0.276 & $0.90(0.58)$ & 0.117 \\
\hline creatinine & & - & $0.00(0.01)$ & 0.942 \\
\hline Urea & & - & $-0.10(0.11)$ & 0.363 \\
\hline Urate & & _- & $0.00(0.00)$ & 0.149 \\
\hline homocysteine & & - & $0.05(0.03)$ & 0.065 \\
\hline modelfit log likelihood & -110.9 & & -78.3 & \\
\hline \multicolumn{5}{|c|}{$\begin{array}{l}\text { Model } 1 \text { adjusted for sex, age, educational level, waist circumference, diabetes, hypertension, } \\
\text { moking and depression. } \\
\text { Model } \mathbf{2} \text { adjusted for sex, age, educational level, waist circumference, diabetes, hypertension, } \\
\text { moking, depression, creatinine, urea, urate and homocysteine. } \\
\text { Bold }=\mathbf{p} \leq \mathbf{0 . 0 5} \text {. }\end{array}$} \\
\hline
\end{tabular}

